\title{
The road home: Returning to pre-Katrina homes during episodes of psychosis
}

\author{
Gayle Pletsch $^{1}$, Christopher Rodgman ${ }^{1}$, Elizabeth Leimbach ${ }^{2}$, Kelly Erwin ${ }^{1}$, Janet Johnson ${ }^{1}$ \\ ${ }^{1}$ Department of Psychiatry and Behavioral Sciences, Tulane University School of Medicine, New Orleans, USA \\ ${ }^{2}$ Department of Psychiatry and Behavioral Sciences, Albert Einstein College of Medicine, New York, USA \\ Email: grpletsch@gmail.com
}

Received 4 December 2012; revised 2 January 2013; accepted 9 January 2013

\begin{abstract}
Hurricane Katrina was a devastating event to New Orleans. There was a mandatory evacuation of the city during which victims in affected areas were not allowed to return for months. Many residents were unable to return to their previous residence due to the destruction of their home or change in ownership. In its aftermath, a phenomenon of displaced residents becoming psychotic and returning to their pre-Katrina homes that they no longer owned became apartment. While the clinical ramifications of these behaviors remain unclear, in the wake of Hurricane Sandy monitoring of psychotic patients for similar behaviors may be warranted. We present two such cases of this phenomenon, colloquially called "Post-Katrina Syndrome” by psychiatrists in the New Orleans area.
\end{abstract}

Keywords: Hurricane Katrina; Psychosis; PTSD; Dissociative Fugue

\section{INTRODUCTION}

Hurricane Katrina was a devastating event to New Orleans. There was a mandatory evacuation of the city during which victims in affected areas were not allowed to return for months. Many residents were unable to return to their previous residence due to the destruction of their home or change in ownership. Some homes were simply gone. Following Katrina, inpatient psychiatric services have resumed at a number of different facilities, including University Hospital, LSU Interim Hospital Behavioral Unit at DePaul Campus, and initially New Orleans Adolescent Hospital. Many residents of New Orleans, including those with severe psychotic illnesses, remain displaced to this day. Over the course of one year of working at DePaul, there was noted a number of cases of psychiatric patients returning to their pre-Katrina home during episodes of acute psychosis, as could be likened to an almost fugue-like state. Patients were studied based on the criteria of having returned from their city of displacement following Katrina in a psychotic episode attempting to enter a home they had owned pre-Katrina but no longer owned after the storm. Our paper presents two patients who in an episode of psychosis returned to their pre-Katrina home. Both seem to have returned home while psychotic in a fugue-like state to reassume their pre-Katrina identities. We deem this behavior PostKatrina Syndrome.

\section{CASES}

A 54-year-old man with a history of schizophrenia was brought in by police after attempting to break into a home in which he used to live. Upon admission to DePaul the patient reported that the home in which he was trying to enter was his own. The patient's sister reported that the patient no longer owned the home, and he had traveled from Georgia in his psychotic state in order to obtain his social security card. The patient also endorsed multiple delusions, such as being Stevie Wonder's son, and the presence of a little black box located in the back of his head from which his auditory hallucinations originated. On admission exam he displayed loose associations, concrete thought processes, grandiose delusions and hyperverbal speech. He complained that he was not sleeping and had been noncompliant with his home medications of fluphenazine and amitryptiline. He had a history of schizophrenia, and first complained of auditory hallucinations at the age of 27. He denied any history of substance abuse, but upon admission, his urine toxicology screen was positive for cannabis. He had been living with his daughter prior to his most recent episode of psychosis, where they had evacuated for Katrina. The patient remained at DePaul for approximately two weeks, and was treated with fluphenazine and valproic acid. At the time of discharge, his association with his pre-Katrina home as that of his current home was no longer present.

Similarly, a 33-year-old man with a history of schizo- 
affective disorder presented to DePaul via New Orleans Police Department Crisis Unit following an episode in which he approached police requesting assistance for finding his home, a home in which he has not resided since the time of Hurricane Katrina. Instead, the patient currently resides with his mother in another home. The patient also believed himself to be Jesus and requested to be addressed as such. His toxicology screen was positive for cannabis. On exam, he displayed thought blocking, grandiose delusions and an expansive affect. At the time of Katrina, the patient was trapped in his home due to the flood waters and had to wade through the water to higher ground at the interstate, whereupon he was taken to the Superdome for evacuation. He had previous admissions to Dr. Janet Johnson's team at DePaul in which he attempted to break into to his pre-Katrina home, episodes that occurred five times within the span of five months. Home medications, which he was non-compliant with, included risperidone. With rapid titration of risperidone, his association with his pre-Katrina residence as his current residence abated following the resolution of his psychosis, as it had with his previous admissions.

\section{DISCUSSION}

\subsection{Overview}

Hurricane Katrina was a devastating event to New Orleans. Many of the city's population did not evacuate the city at the time of the mandatory evacuation and were thus subjected to rapidly rising water after the levees broke, some having to take refuge on their rooftops for days until boat or helicopter transportation was arranged. Many psychiatric patients remained in Charity Hospital's Psychiatric floor until such a time as they could be transported to outside facilities. It took five days to completely evacuate Charity Hospital.

It is estimated that 40 to 100 billion dollars of damage was sustained by the city [1,2]. Its residents were displaced for months. Estimated population in federal emergency management agency (FEMA) damaged areas was estimated at 137,668 (37.2\%) total, and 37,336 (10.1\%) catastrophically damaged [3]. Two-hundred-thousand residents were left homeless in Louisiana [4]. Complete restoration effort is estimated to take up to 11 years [1]. Death toll was estimated at 971 to 1570 , with more than 1800 missing $[1,4,5]$. In the overall population, the prevalence of post-traumatic stress disorder increased from $14.9 \%$ to $20.9 \%$, serious mental illness from $10.9 \%$ to $14 \%$, and suicidal ideation from $2.8 \%$ to $6.4 \%$ [6]. Anecdotally it has been noted that many patients had their first psychotic break in relation to the storm.

There was initially an interruption in psychiatric care as our patients were displaced to various cities. Many were unable to contact their physicians or were unaware of their medications or unable to obtain their medications or medical records. Upon return to the city there was a further delay in treatment as many facilities, services, medical records, and physicians available prior to the storm had washed away, lost funding, closed or relocated. Not only did our psychiatric patients sustain a severe traumatic event, but were subjected to a loss of social structure and support, and return to normalcy following the storm. Many have yet to return to their previous level of functioning, cities, or residences. Many lost family members and friends.

Following Katrina, inpatient psychiatric services have resumed at a number of different facilities, including University Hospital, LSU Interim Hospital Behavioral Unit at DePaul Campus, and initially New Orleans Adolescent Hospital. Over the course of six months of working at DePaul, there was noted a number of cases of psychiatric patients returning to their pre-Katrina home during episodes of acute psychosis, as could be likened to an almost fugue-like state.

\subsection{Diagnosis}

According to the DSM-IV-TR, a dissociative disorder is one in which there is a disruption of consciousness, memory, identity, or perception, usually in response to a traumatic event [7]. Dissociative fugue involves sudden unexpected travel with the inability to recall some or all of one's past, and involving amnesia for the fugue period [7]. However, for dissociative fugue as according to Kaplan and Saddock, our patients do not meet actual criteria given that their loss of memory and wandering are due to psychosis [8]. None-the-less, our patients did experience travel to another location, with assumption of a previous identity.

Dissociative symptoms have been linked to female sex, proximity to disasters, and previous stressful life events. It has been noted that greater exposure equals greater dissociative and anxiety symptoms after exposure. Potential dangerous actions taken (such as trying to get nearer to the event versus evacuating or packing one's possessions) lead to an increase in dissociative symptoms [9]. Resource loss and prior history of trauma are also associated with psychiatric distress [10]. High dissociators are more likely to worry about loved ones, to watch media related to the event, and more likely to increase food intake to distract them from thinking about the disaster [9]. Regarding the Okalahoma City Bombing intrusivistic and hyperarousal PTSD symptoms were universal but not associated with functional impairment. However, dissociative symptoms such as avoidance, detachment, and numbing had a high association with psychiatric comorbidity, impairment, and the need for treatment [11]. Schizophrenia in and of itself is associa- 
ted with detachment and negative symptoms, and it could be postulated that these features make this population more likely to dissociate.

Although there is limited data regarding dissociation in psychotic patients, there is a preponderance of data related to PTSD and dissociation. For example, in a comparison of responders versus non-responders in the world trade center disaster, premorbid dissociation was the strongest predictor of post event dissociation, and premorbid PTSD was the strongest predictor of posttraumatic stress. Poor prognostic indicators were feelings of guilt and shame with persistent dissociation. Loss of control was a predictor of dissociation and PTSD. Decreased outcome was also associated with decreased social support after the event and greater co-morbid dissociation. Those that remained impaired were those with detachment and avoidant type PTSD symptoms [12]. Our population certainly had decreased social support from their city and the wide range of locations to which they and their families and friends were evacuated, as well as decreased psychiatric services upon their return to the city.

There has certainly been case reports of dissociative fugues, such as one veteran who disappeared on multiple occasions during a dissociative fugue into nearby woods resembling those in which he had served during the war, and when found had no memory of the missing hours or even months [13]. According to Young, it is not necessarily a new but can also be a prior identity that is assumed, as with Macleod's veteran, and which could be considered a parallel with our patients returning to previous homes [14].

\subsection{Treatment}

The Patients with dissociative disorders and dissociative fugue often resolve on their own upon removal from traumatic episodes, but in the case of dissociative fugue, dissociative amnesia may persist. In depersonalization disorders and dissociative identity disorders, the course is generally chronic with waxing and waning depending on patient condition [7]. The treatment options for PTSD are extensive and are covered heavily in other sources. With our patients, association with pre-Katrina identities and homes was ameliorated by antipsychotic medications, fluphenazine in the first patient and risperidone in the second. It appears, then, that both first and second generation antipsychotics can be helpful in the treatment of these conditions.

\section{CONCLUSION}

Since Hurricane Katrina, a number of patients have presented to DePaul Behavior Health Hospital under the care of Dr. Janet Johnson and her team with a similar clinical picture to the patient we present. We postulate that these patients assume their pre-Katrina identity during episodes of psychosis, in a fugue-like state. This behavior, while likely more closely resembling PTSD symptoms in those with severe psychotic illnesses and not necessarily constituting a new diagnosis, has been referred to colloquially by psychiatrists in New Orleans as "Post-Katrina Syndrome". Clinical implications of this pattern are as yet unclear, however in the wake of Hurricane Sandy close monitoring of psychotic patients in the North Eastern United States may demonstrate similar behaviors. Further investigation is needed to determine risk factors and characteristics of this population.

\section{ACKNOWLEDGEMENTS}

The authors would like to thank specifically Dr. Daniel Winstead, Dr. L. Lee Tynes, and Dr. Erik Kinzie. We also could not have succeeded without the help of Julie Ray and Violet Robert.

\section{REFERENCES}

[1] Kates, R.W., Colten, C.E., Laska, S. and Leatherman, S.P. (2006) Reconstruction of New Orleans after Hurricane Katrina: A research perspective. Proceedings of the $\mathrm{Na}$ tional Academy of the Sciences of the Unites States of America, 103, 14653-14660.

[2] Rosenbaum, S. (2006) US health policy in the aftermath of Hurricane Katrina. The Journal of the American Medical Association, 295, 437-440.

[3] Richard, B. Initial Estimate of the Impacts of Hurricane Katrina. December 2005. http://www.usm.edu/gulfcoast/katrina-research-center

[4] Louisiana Geographic Information Center, (2005) Louisiana hurricane impact atlas, $\mathbf{1}$.

[5] Brunkard, J., Namulanda, G. and Ratard, R. (2008) Hurricane Katrina Deaths, Louisiana, 2005. Disaster Medicine and Public Health Preparedness, 2, 215-223. doi:10.1097/DMP.0b013e31818aaf55

[6] Kessler, R.C., Galea, S., Gruber, M.J., Sampson, N.A., Ursano, R.J. and Wessely, S. (2008) Trends in mental illness and suicidality after Hurricane Katrina. Molecular Psychiatry, 13, 374-384. doi:10.1038/sj.mp.4002119

[7] American Psychiatric Association (2000) Diagnostic and Statistical Manual of Mental Disorders (DSM-IV-TR). 4th Edition, American Psychiatric Press, Arlington, 519533.

[8] Kaplan, H.I. and Sadock, B.J. (1998) Dissociative disorders. Synopsis of psychiatry, behavioral sciences-clinical psychiatry, 8th Edition, Lippincott, Williams \& Wilkins, Baltimore, 660-675.

[9] Koopman, C., Classen, C. and Spiegel, D. (1996) Dissociative responses in the immediate aftermath of the oakland/berkeley firestorm. Journal of Traumatic Stress, 9, 521-540. doi:10.1002/jts.2490090309

[10] Freedy, J.R., Saladin, M.E., Kilpatrick, D.G., Resnick, H.S. and Saunders, B.E. (1994) Understanding acute psychological distress following natural disasters. Journal of 
Traumatic Stress, 7, 257-273.

doi:10.1002/jts.2490070207

[11] North, C.S., Nixon, S.J., Shariat, S., et al., (1999) Psychiatric disorders among survivors of the Oklahoma City bombing. Journal of the American Medical Association, 282, 755-762. doi:10.1001/jama.282.8.755

[12] Simeon, D., Greenberg, J., Nelson, D., Schmeidler and J., Hollander, E. (2005) Dissociation and posttraumatic stress one year after the world trade center disaster: Follow-up of a longitudinal survey. Journal of Clinical Psy- chiatry, 66, 231-237. doi:10.4088/JCP.v66n0212

[13] Macleod, A.D. (1999) Posttraumatic stress disorder, dissociative fugue and a locator beacon. Australian and New Zealand Journal of Psychiatry, 33, 102-104. doi:10.1046/j.1440-1614.1999.00514.X

[14] Young, W.C. (1987) Emergence of a multiple personality in a post traumatic stress disorder of adulthood. American Journal of Clinical Hypnosis, 29, 249-254. doi:10.1080/00029157.1987.10402704 